\title{
Avaliação do perfil cromatográfico e do teor de flavonóides em amostras de Baccharis trimera (Less.) DC. Asteraceae (carqueja) comercializadas em Ribeirão Preto, SP, Brasil
}

\author{
Borella, J. C.*; Fontoura A. \\ Disciplina de Farmacognosia, Curso de Ciências Farmacêuticas, \\ Universidade de Ribeirão Preto, Ribeirão Preto, SP.
}

Recebido para publicação em: 17/07/2002

Aceito para publicação em: 13/09/2002.

RESUMO: Oito amostras de Baccharis trimera (Less.) DC., Asteraceae (carqueja), adquiridas no comércio de Ribeirão Preto, SP, foram analisadas quanto ao seu perfil cromatográfico e teor de flavonóides. O material obtido de um exemplar autêntico de B. trimera foi utilizado como padrão. A análise do perfil cromatográfico foi realizada através de cromatografia em camada delgada e o teor de flavonóides foi determinado por método espectrofotométrico. Verificou-se que as amostras analisadas exibem o mesmo perfil cromatográfico da droga vegetal padrão e a análise do teor de flavonóides (\% p/p estimada como rutina) mostrou que há uma grande variação entre as amostras.

Unitermos: Baccharis trimera; carqueja; flavonóides; controle de qualidade.

ABSTRACT: Evaluation of the chromatographic profile and flavonoid content of samples of Baccharis trimera (Less.) DC., Asteraceae (carqueja) acquired in Ribeirão Preto, SP, Brazil. The chromatographic profile and the flavonoid content of samples of Baccharis trimera (Less.) DC., Asteraceae (carqueja), acquired in Ribeirão Preto, SP, Brazil were evaluated. For this characterization a qualitative analysis was performed by using thin-layer chromatography, and the total flavonoid content was quantified through a spectrophotometric method. The chromatographic profiles of all the samples showed to be similar to that of the reference material, but there is a high variation in the content of total flavonoids (\% w/w estimated as rutin).

Key words: Baccharis trimera; carqueja; flavonoids; TLC profile; quality control

\section{INTRODUÇÃO}

A família Asteraceae concentra grande número de espécies com potencial terapêutico, algumas das quais do gênero Baccharis, utilizadas na medicina popular e também na produção de fitoterápicos. A principal indicação mencionada para estas espécies recai sobre suas ações sobre o aparelho digestivo, sobretudo relacionadas com as funções hepáticas e biliares (SIMÕES et al., 1986). Baccharis trimera (Less.) DC. ou Baccharis genistelloides var. trimera (Less.) Baker é uma das espécies mais utilizadas para estes fins. Para ela, foi relatada a presença de monoterpenos, diterpenos, sesquiterpenos e esteróis (SOUSA et al., 1991), além de saponinas (GENÉ et al., 1996). Lactonas diterpênicas, presentes no extrato 
clorofórmico de $B$. trimera, tiveram seus efeitos relaxantes da musculatura lisa vascular evidenciados por Torres et al. (2000). Uma série de flavonóides, como eupatorina, eupatrina, cirsimaritina, circiliol, genkwanina, eriodictiol, canferol (SOUSA et al., 1991), quercetina, luteolina, nepetina, apigenina e hispidulina (SOICKE et al., 1987), também, foram obtidos de $B$. trimera. Alguns desses flavonóides mostraram ter atividade moluscicida (DOS SANTOS FILHO et al., 1980) e anti-hepatotóxica (SOICKE et al., 1987). Gené et al. (1996) demonstraram efeitos antiinflamatório e analgésico para extratos de $B$. trimera, em ratos. Ficou evidenciado que as responsáveis por tais ações foram a rutina e uma mistura de saponinas. Sendo assim, a utilização desta espécie, na fitoterapia, como anti-hepatotóxica, antiinflamatória e analgésica parece ter respaldo científico; no entanto, a eficácia desses tratamentos está relacionada com a qualidade dos recursos terapêuticos utilizados. Análises realizadas com plantas medicinais e fitoterápicos existentes no mercado (LEITE et al. 1996; ZOUPA et al. 2000; BARBOSA et al. 2001; BRANDÃO et al. 2001) evidenciaram a péssima qualidade desses produtos, apesar das legislações vigentes (Port. 6/SVS de 31/01/1995, DOU de 06/02/1995, reformulada através da Resolução RDC n.17 de 24/02/2000), do desenvolvimento de metodologias analíticas (MELLO e PETROVICK, 2000) e dos métodos de cultivo (BORELLA et al. 2001), que foram elaborados para melhorar esta situação.

Este estudo foi realizado com o objetivo de estabelecer a composição química (perfil cromatográfico e quantificação de flavonóides) de algumas amostras de $B$. trimera, adquiridas no comércio de Ribeirão Preto, SP, verificando, ainda, a variabilidade da composição flavonoídica das mesmas.

\section{MATERIAIS E MÉTODOS}

\section{Material vegetal}

Oito amostras de Baccharis trimera foram adquiridas no comércio de Ribeirão Preto, em mercados, feiras, supermercados e farmácias de manipulação. Estas se apresentavam de diversas formas: quatro eram constituídas por partes aéreas secas do vegetal (amostras I a IV); duas eram constituídas pela droga pulverizada, acondicionadas em sacos plásticos (amostras $\mathrm{V}$ e $\mathrm{VI}$ ); uma era constituída por droga pulverizada e acondicionada em sachês (amostra VII) e uma era constituída pela droga pulverizada, acondicionada em cápsulas gelatinosas de $500 \mathrm{mg}$ (amostra VIII). Todas as amostras adquiridas citaram o nome oficial da espécie (Carqueja Amarga), segundo a Farmacopéia Brasileira 1a edição (1926); no entanto, alguns produtos (amostras $\mathrm{V}$ a VIII) citavam, ainda, a designação latina da espécie em suas embalagens.

\section{Droga vegetal padrão}

A droga vegetal padrão, utilizada na comparação do perfil cromatográfico e nas análises quantitativas, foi obtida através de cultivo de B. trimera e foi identificada pelo Prof. Ademar Menezes Júnior, da Unidade de Biotecnologia, da Universidade de Ribeirão Preto. Após seis meses de desenvolvimento, esse material foi colhido e secado em estufa $\left(30^{\circ} \mathrm{C}\right)$. Um exemplar do material utilizado foi depositado no Herbário da Unidade de Biotecnologia Vegetal da Universidade de Ribeirão Preto, exsicata n.25. Aquelas amostras que não estavam pulverizadas, inclusive a droga vegetal padrão, foram submetidas à moagem, em moinho de facas e, posteriormente, tamisadas (tamis II) para uniformidade da granulometria. 


\section{Cromatografia em camada delgada}

A caracterização das amostras foi realizada por cromatografia em camada delgada, utilizando para fins comparativos a droga vegetal padrão. Os extratos analisados foram obtidos segundo técnica descrita pela World Health Organization (1992), utilizando metanol como solvente. As amostras e os padrões foram aplicados, em igual volume, em placas cromatográficas de gel de sílica GF $_{254+366}$, (Merck) utilizando como fase móvel n-butanol : ácido acético : água (50:10:25). As revelações foram feitas através de luz ultravioleta (254 e $366 \mathrm{~nm}$ ) e nebulização de ácido sulfúrico com posterior aquecimento a $110^{\circ} \mathrm{C}$, por $3 \mathrm{~min}$.

\section{Doseamento}

Os teores de flavonóides das amostras e da droga vegetal padrão foram estabelecidos por método espectrofotométrico, segundo técnica descrita por Costa (1982). Após extração e purificação da fração flavonoídica, foi feita a reação com cloreto de alumínio e, após 15 min foi realizada a leitura, em $420 \mathrm{mn}$. Utilizou-se a rutina para confecção da curva de dosagem. Todas as análises espectrofotométricas foram realizadas em triplicata. Com esses resultados foi feita análise de variância (ANOVA) seguida do teste de comparações múltiplas (Tukey-Kramer), tomando-se o valor de $p<0,05$ como nível máximo de significância estatística.

\section{RESULTADOS E CONCLUSÃO}

Após as análises, obteve-se perfis cromatográficos muito semelhantes entre todas as amostras e a droga vegetal padrão. Com relação ao teor de flavonóides (Figura 1), tendo como base os resultados das análises estatísticas, ficou evidente a grande variabilidade dos teores dessas substâncias, nas amostras analisadas. Entre todas as amostras, somente a I e a III não diferiram estatisticamente entre si, até o nível de $5 \%$ pelo teste de TukeyKramer. Todas as demais amostras, inclusive em comparações feitas com a droga vegetal padrão, mostraram ter valores distintos. Deste modo, conclui-se que, apesar de não haver grandes diferenças qualitativas em relação à composição química das amostras analisadas, a maioria destes materiais diferem substancialmente no teor de um dos grupos de substâncias ativas (flavonóides). Tal variação pode ter ocorrido por vários fatores, tais como aqueles relacionados ao cultivo, fatores ambientais, local de coleta, idade da planta, e preparo e manipulação da droga vegetal, podendo ter ocorrido, no decorrer deste processo, adulterações e/ou falsificações. 


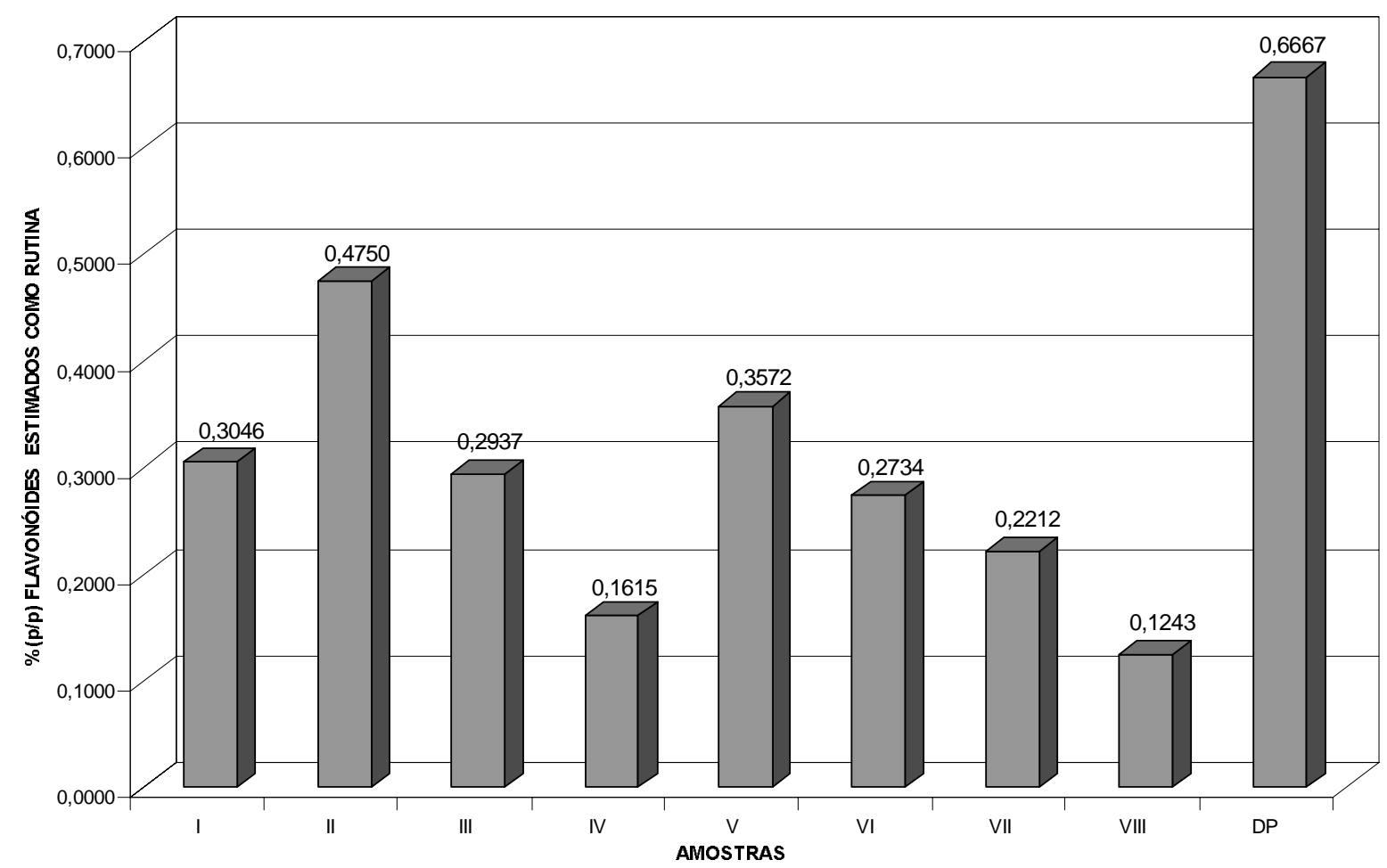

Figura 1. Teores de flavonóides, determinados por espectrofotometria (420mn), em amostras de carqueja, adquiridas no comércio de Ribeirão Preto, SP (média de três determinações). $\mathrm{DP}=$ droga vegetal padrão

\section{AGRADECIMENTOS}

Os autores agradecem ao Prof. Ademar Menezes Júnior, da Unidade de Biotecnologia da Universidade de Ribeirão Preto pela identificação e fornecimento de partes aéreas de Baccharis trimera necessárias para a execução deste trabalho.

\section{REFERÊNCIAS BIBLIOGRÁFICAS}

BARBOSA, M. C. S.; BELLETTI, K. M. S.; CORRÊA, T. F.; SANTOS, C. A. M. Avaliação da qualidade de folhas de boldo-do-chile (Peumus boldus Molina) comercializadas em Curitiba, PR. Revista Brasileira de Farmacognosia, v.11, p.1-4, 2001.

BORELLA, J. C.; FONTOURA, A.; MENEZES JR., A.; FRANÇA, S. C. Influência da adubação mineral e da sazonalidade no rendimento e teor de flavonóides em indivíduos masculinos de Baccharis trimera (Asteraceae - Carqueja). Revista Brasileira de Plantas Medicinais, v.4, p.99-102, 2001.

BRANDÃO, M. G. L.; OLIVEIRA, P.; MOREIRA, R. L.; ALVES, R. M. S.; VIEIRA M. T.; CAMPOS, L. M. M. Qualidade de amostras comerciais de plantas medicinais e produtos fitoterápicos: drogas inscritas na farmacopéia brasileira. Infarma, v.13, p.60-61, 2001.

COSTA, A. F. Farmacognosia - farmacognosia experimental. 2.ed. Lisboa: Calouste Gulbenkian, p.756769, 1982. 
DOS SANTOS FILHO, D.; SARTI, S. J.; VICHNEWSKI, W.; BULHÕES, M. S.; LEITÃO FILHO, H. F. Atividade moluscicida em Biomphalaria glabrata, de uma lactona diterpênica e de uma flavona isoladas de Baccharis trimera (Less.) A.P. de Candole. Revista da Faculdade de Farmácia e Odontologia de Ribeirão Preto, v.17, n.1, p.43-47, 1980.

FARMACOPÉIA Brasileira. São Paulo: Nacional. p.186-187, 1926.

GENÉ, R. M.; CARTAÑÁ, C.; ADZET, T.; MARÍN, E.; PARELLA, T.; CAÑIGUERAL, S. Anti-inflammatory and analgesic activity of Baccharis trimera: identification of its active constituents. Planta Medica, v.62, p.232235, 1996.

LEITE, S. N.; BIAVATTI, M. W. Avaliação da qualidade de chás medicinais e aromáticos comercializados em Itajaí, SC. Revista Brasileira de Farmacognosia, v.5, p.175-184, 1996.

MELLO, J. C. P.; PETROVICK, P. R. Quality control of Baccharis trimera (Less.) DC. (Asteraceae) hydroalcoholic extracts. Acta Farmaceutica Bonaerence, v.19, p.211-215, 2000.

SIMÕES, C. M. O.; MENTZ, L. A.; SCHENKEL, E. P.; IRGANG, B. E.; STEHMANN, J. R. Plantas da medicina popular no Rio Grande do Sul. Porto Alegre: Ed. da Universidade. p.42-43, 1986.

SOICKE, H.; LENG-PESCHLOW, E. Characterization of flavonoids from Baccharis trimera and their antihepatotoxic properties. Planta Medica, v.53, p.37-39, 1987.

SOUSA, M. P.; MATOS, M. E. O.; MATOS, F. J. A.; MACHADO, M. I. L.; CRAVEIRO, A. Constituintes químicos ativos de plantas medicinais brasileiras. Fortaleza: UFC, p.223-228. 1991.

TORRES, L. M.; GAMBERINI, M. T.; ROQUE, N. F.; LANDMAN, M. T.; SOUCCAR, C.; LAPA, A. J. Diterpene form Baccharis trimera with a relaxant effect on rat vascular smooth muscle. Phytochemistry, v. 55, p.617619, 2000.

WORLD HEALTH ORGANIZATION. Quality control methods for medicinal plant materials. Genebra: WHO, p.20-22. 1992.

ZOUPA, C.; CARRASCHI, L.; SILVA, E. A.; CHANKE, A. L. S.; USHIROBIRA, T. M. A.; MARQUES, L. C. Controle de qualidade farmacobotânico e legal de fitoterápicos comercializados nas farmácias de Maringá (PR). Revista Racine, v.58, p.32-36, 2000.

* Autor para correspondência:

Prof. Dr. Júlio Cézar Borella

Curso de Ciências Farmacêuticas

Universidade de Ribeirão Preto (UNAERP)

Av. Costabile Romano, 2201 - Ribeirânia

14096-380 - Ribeirão Preto - SP

e-mail: jborella@online.unaerp.br 